\author{
Rezky Diningrat Khan ${ }^{1}$ dan Ratri Wulandari ${ }^{2}$ \\ Program Studi Desain Interior \\ Universitas Telkom \\ ${ }^{1}$ rezkykhan42@gmail.com \\ ${ }^{2}$ ratriwulandari@telkomuniversity.ac.id
}

\title{
STUDI KOMPARASI FASILITAS DAN STANDAR ASRAMA DI INDONESIA: Studi Kasus 5 Universitas
}

\begin{abstract}
Abstrak: Asrama merupakan hunian atau bangunan tempat tinggal bagi kelompok orang untuk sementara waktu, terdiri atas sejumlah kamar, asrama yang dirancang dan dibangun dengan standar-standar khusus sesuai dengan jenjang usia penghuninya (KBBI). Di Indonesia keberadaan asrama mahasiswa mulai menjadi perhatian karena mampu menampung mahasiswa untuk tinggal dalam lingkungan kampus. Banyak kampus sekarang menyediakan fasilitas asrama bagi mahasiswanya. Satu hal yang diperhatikan saat membangun asrama adalah daya tampung dan ketersediaan lahan. Untuk itu fasilitas utama yang menjadi perhatian adalah kamar. Padahal diperlukan fasilitas lain dalam asrama selain kamar, karena kegiatan di asrama tidak hanya tidur, tetapi juga belajar, bersosialisasi, makanminum, aktivitas domestik (mencuci-memasak) maupun kegiatan higienis pribadi. Dalam penelitian kali ini akan dibahas mengenai perbandingan standar-standar dan fasilitas yang ada dalam sebuah asrama serta untuk mengetahui tipologi asrama di universitas-universitas Indonesia dengan metode penelitian kualitatif deskriptif dengan mengambil sampel 5 asrama universitas sebagai studi kasus, diantaranya ialah ITB, Unpad, UGM, UI dan Telkom University.

Fasilitas terlengkap ditemukan pada asrama Unpad Bale Padjadjaran dengan total 15 jenis fasilitas, diikuti asrama UGM dengan 14 jenis fasilitas. Ditemukan bahwa luas kamar setiap asrama berbeda-beda. Meskipun demikian, berdasarkan pengamatan, ditemukan bahwa luas setiap kamar telah sesuai dengan standar minimum berdasarkan standar internasional. Didapatkan 3 tipologi kamar dari hasil perbandingan ini, yaitu kamar untuk 2-3 orang, kamar semi kluster dan kamar yang dihuni 4 orang. Dari data hasil komparasi dapat disimpulkan bahwa terdapat keragaman fasilitas dan perbedaan peruntukkan asrama universitas di Indonesia.
\end{abstract}

Kata Kunci: Asrama, Standar, Fasilitas

\begin{abstract}
Dormitory is dwelling or building of residence for groups of people for a certain time period, it consisted of numbers of rooms, dormitory designed and built according to specific standards corresponding with the age of its inhabitants (KBBI). In indonesia the existence of student dormitory begins to attract attention since it can accommodate students to dwell within campus environment. Many campuses now provide a hall of residence facility for their students. One consideration in constructing a student hall of residence is capacity and the availability of land. Therefore, main facility with largest concern is room. On the other hand, other facilities besides room is required in dormitory or residence hall because the activities in a residence hall is not only sleeping, but also they also studying, socializing, eating-drinking, domestic activities (washing-cooking) or personal hygiene activities. The research will discuss the comparison of standards and facilities is in a residence hall, as well as to know typologies
\end{abstract}


of residence hall in Indonesian universities using descriptive qualitative research methodology by taking samples of 5 universities dormitory (residence hall) as case study which are residence hall of ITB, Unpad, UGM, UI and Telkom University.

Most complete facilities found in Unpad Bale Padjadjaran residence hall with a total of 15 facilities, followed UGM residence hall with 14 facilities. It was found that the area of each room differs. However, based on observations, it was found that the area of each room is in accordance to minimum standard based on international standards. Three room typologies were obtained from these comparisons, which are room for 2-3 people, the semi cluster suite and room inhabited by 4 people. From this comparison data, it can be concluded that there are varieties of facilities and differing allocation of residence hall in Indonesian universities.

Keywords: Dormitory, Standard, Facilities

\section{Pendahuluan \\ 1.1 Latar Belakang}

Asrama adalah hunian bersama bagi pelajar yang dibangun dalam berbagai skala, mulai dari skala kecil (sampai 50 penghuni) hingga skala sangat besar dengan penyediaan lebih dari 200 kamar. Di berbagai negara maju, asrama ini telah dirancang dan dibangun dengan standarstandar khusus sesuai dengan jenjang usia penghuninya. Di negara-negara Eropa, asrama mahasiswa atau lebih dikenal dengan student housing banyak disediakan oleh pihak universitas untuk mewadahi kebutuhan hunian mahasiswa yang berasal dari luar kota, bahkan luar negeri.

Di Indonesia keberadaan asrama mahasiswa mulai menjadi perhatian karena mampu menampung mahasiswa untuk tinggal dalam lingkungan kampus. Banyak kampus sekarang menyediakan fasilitas asrama bagi mahasiswanya. Bahkan pembangunan asrama baru banyak dilakukan oleh pihak univeristas baik negeri maupun swasta. Desain asrama beragam antar penyedia. Satu hal yang diperhatikan saat membangun asrama adalah daya tampung dan ketersediaan lahan. Untuk itu fasilitas utama yang menjadi perhatian adalah kamar. Padahal diperlukan fasilitas lain dalam asrama selain kamar, karena kegiatan di asrama tidak hanya tidur, tetapi juga belajar, bersosialisasi, makan-minum, aktivitas domestik (mencuci-memasak), kegiatan higienis pribadi. Hal selanjutnya pun perlu menjadi perhatian perancang dalam merancang asrama.

\section{$1.2 \quad$ Tujuan}

Penelitian Komparasi Standar dan Fasilitas Asrama ini dilakukan untuk mengetahui ragam dan standar fasilitas asrama yang disediakan oleh universitas-universitas di Indonesia. Pengetahuan akan fasilitas-fasilitas yang disediakan, jenis layanan, pertuntukkan (tipe atau kelas 
mahasiswa yang ditempatkan/diterima) dan kualitas ruang turut menjadi tujuan penelitian ini untuk mengetahui tipologi asrama di universitas-universitas di Indonesia.

\section{Kajian Literatur}

\subsection{Asrama Mahasiswa}

Dalam bahasa Inggris, asrama dikenal dengan istilah dormitory atau residence hall untuk tingkat universitas. Kamus Mirriam-Webster mendefinisikan dormitory sebagai 1: a room for sleeping; especially: a large room containing numerous beds; 2: a residence hall providing rooms for individuals or for groups usually without private baths. Istilah residence hall lebih sering digunakan untuk terminologi asrama mahasiswa karena terdapat perbedaan fasilitas dengan dormitory. Sementara dormitory lebih banyak digunakan dalam konteks asrama sekolah karena identik dengan fasilitas kamar tidur dengan banyak tempat tidur. Asrama mahasiswa umumnya dipisahkan berdasarkan gender dan dibagi ke dalam asrama putra dan asrama putri.

Dalam konteks Indonesia, menurut KBBI, asrama merupakan bangunan tempat tinggal bagi kelompok orang untuk sementara waktu, terdiri atas sejumlah kamar, dan dipimpin oleh seorang kepala asrama. Berdasarkan Keputusan Presiden Nomor 40/1981 Asrama mahasiswa diartikan sebagai suatu lingkungan perumahan sebagai tempat tinggal mahasiswa, yang dalam perkembangan lebih lanjut, dimungkinkan memiliki sarana lingkungan untuk melengkapinya, seperti perpustakaan, pengadaan buku, kantin, olah raga dan sarana lainnya yang diperlukan yang dikelola oleh mahasiswa dalam bentuk koperasi.

Dari Keppres tersebut dapat disimpulkan bahwa asrama mahasiswa tidak hanya fasilitas tidur biasa, melainkan suatu lingkungan perumahan (terdapat fasilitas tinggal dan berkegiatan domestik) yang dapat diberi fasilitas tambahan seperti perpustakaan, kantin, koperasi, sarana olahraga. Keppres tidak menyebutkan fasilitas komunitas seperti ruang belajar bersama ataupun ruang komunal lainnya yang sebetulnya diperlukan penghuni.

\subsection{Standar Ukuran Asrama}

Berdasarkan Buku de Chiara, Time Saver Standards for Building Types mengenai persyaratan ruang area, ukuran asrama yang digunakan adalah:

Tabel 1. Room Area Chart

\begin{tabular}{|c|c|c|}
\hline $\begin{array}{c}\text { Number of double } \\
\text { bunks }\end{array}$ & Number of people & $\begin{array}{c}\text { Min. Area needed (sq } \\
\mathrm{ft})\end{array}$ \\
\hline 2 & 4 & 120 \\
\hline
\end{tabular}




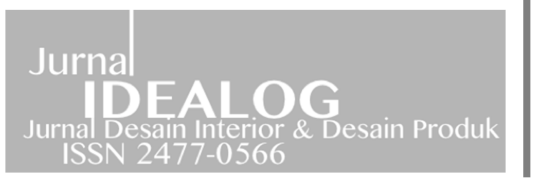

\begin{tabular}{|c|c|c|}
\hline 4 & 8 & 240 \\
\hline 6 & 12 & 360 \\
\hline 8 & 16 & 480 \\
\hline 10 & 20 & 600 \\
\hline 12 & 24 & 720 \\
\hline 14 & 28 & 840 \\
\hline 16 & 32 & 960 \\
\hline
\end{tabular}

Minimun ketinggian langit-langit adalah 8 kaki atau 2,4 $\mathrm{m}$

Sumber: Time Saver Standarts For building Types 2nd edition, Joseph De Chiara And John Hancock

Callender May 1975

Time Saver Standards for Building Types menyebutkan bahwa luas ruangan minimum untuk satu kamar dengan 2 tempat tidur tingkat yang dihuni 4 orang adalah 120 kaki persegi atau $\pm 11 \mathrm{~m}^{2}$. Dapat dipahami juga jika di kamar tersebut ditempatkan 2 tempat tidur tidak bertingkat, maka luasan yang dibutuhkan kurang lebih sama karena angka tersebut memperhitungkan area yang dibutuhkan oleh tempat tidur. Luasan kamar asrama dipengaruhi oleh banyaknya penghuni, jumlah tempat tidur yang digunakan dan jenis tempat tidur yang digunakan.

Pada umumnya, kamar asrama yang dihuni oleh 2 atau lebih orang menggunakan tempat tidur double decker/double bunk untuk mengoptimalkan luas kamar agar dapat menampung banyak penghuni.
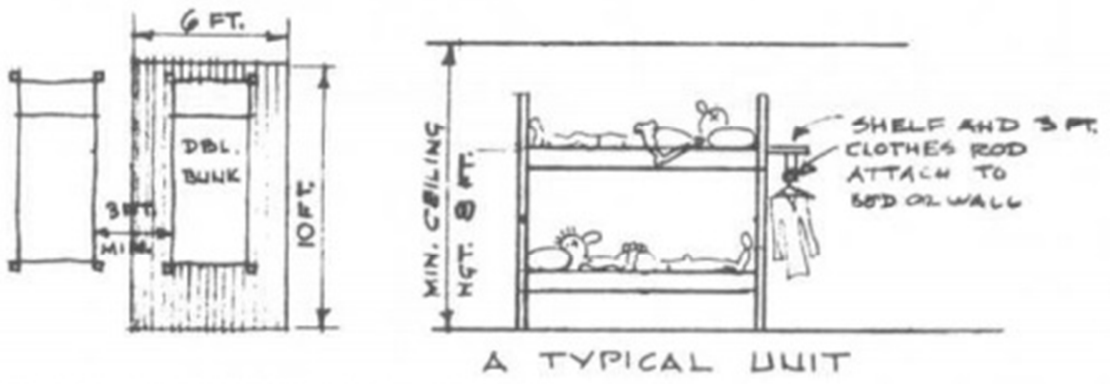

Gambar 2.1. Area minimum per double bunk, $60 \mathrm{sq} f \mathrm{ft}$

Sumber: Time Saver Standarts For building Types 2nd edition, Joseph De Chiara And John Hancock

Callender May 1975

Pada gambar 2.1 terlihat bahwa ketinggian minimum langit-langit disarankan setinggi $2,4 \mathrm{~m}$ yang sebetulnya tidak cukup untuk menampung kegiatan duduk orang yang tidur di tempat 


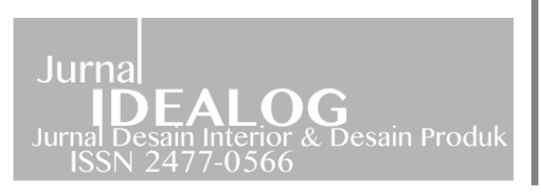

tidur tingkat kedua. Ketinggian tersebut juga berakibat pada ketinggian tempat tidur bagian bawah yang juga rendah.

\subsection{Jenis Kamar Asrama dan Fasilitas}

Berbagai artikel ilmiah yang membahas asrama memberikan contoh tipe kamar yang berbeda-beda. Dari berbagai artikel tersebut, tipe kamar yang umum disediakan di asrama antara lain sebagai berikut:

a. Single Rooms - kamar individual dihuni oleh satu orang.

b. Double Rooms - kamar dihuni 2 orang

c. Triple Rooms - kamar dihuni 3 orang

d. Four - Student Rooms - kamar dihuni 4 orang

e. Dorm room - kamar dihuni oleh lebih dari 4 orang. Kamar tipe ini digunakan di Eropa dan Amerika era 1950-1970 dan telah ditinggalkan.

f. Suite Room - kluster 3-4 kamar individual yang masing-masing dihuni satu sampai 2 orang dengan fasilitas ruang bersama sebagai penghubung.

Muslim et al. (2012) melakukan studi kepuasan mahasiswa terhadap tempat tinggalnya terkait jenis layanan dan fasilitas yang ditawarkan. Muslim et al. menemukan dalam artikel yang ditulis Li et al. dalam Thomsen (2008) bahwa di asrama mahasiswa senang dengan keberadaan ruang makan dan akses internet berkecepatan tinggi, sementara mereka tidak menyukai kesulitan memasak (tidak tersedia fasilitas memasak), kamar mandi bersama, minim tempat parkir, peluang belajar di tempat tinggal (ketiadaan fasilitas belajar). Muslim et al. (2012) menambahkan bahwa saat ini terdapat kebutuhan terhadap fasilitas tambahan seperti area olahraga/fitness, area rekreasi, jaringan nirkabel. Dari tulisan Muslim et al. (2012) dapat disimpulkan bahwa setidaknya diperlukan fasilitas bersama sebagai berikut dalam sebuah asrama:
a. Ruang makan
b. Dapur
c. Kamar mandi pribadi
d. Area belajar
e. Area olahraga
f. Area rekreasi
g. Jaringan internet kecepatan tinggi
h. Area parkir

Dalam Keppres yang dibahas sebelumnya, disebutkan juga fasilitas bersama sebuah asrama yang meliputi:
a. perpustakaan,
b. kantin, 


\section{c. koperasi, \\ d. sarana olahraga}

Amole (2010) menambahkan perlunya fasilitas laundry untuk mewadahi kebutuhan perilaku domestik mahasiswi dan juga sebagai area komunal tempat berinteraksi.

\section{Metode Penelitian}

Penelitian menggunakan metoda penelitian kualitatif deskriptif dengan model perbandingan objek melalui tabel dan check list. Data dikumpulkan melalui pencarian di situs internet diikuti dengan proses konfirmasi langsung pada pengguna terkait kebenaran data di situs web tersebut. Seluruh data yang terkumpul kemudian disusun dalam tabel komparasi (perbandingan) untuk dilakukan pengamatan dan analisa kondisi asrama terkait kelengkapan fasilitas dan jenis layanan yang diberikan oleh setiap kampus, serta tipe mahasiswa dan pola perlakuan yang diterapkan di setiap asrama. Kelengkapan ini dibandingkan dengan kebutuhan fasilitas asrama hasil studi berbagai peneliti yang dibahas pada kajian literatur.

\section{Pembahasan}

\subsection{Perbandingan Fasilitas Asrama Lima Universitas}

Pada penelitian ini beberapa contoh asrama universitas, terutama asrama yang dibangun dan dikelola universitas negeri besar, dikumpulkan untuk dibuat perbandingan dalam hal luas kamar, lay out ruang, dan fasilitas pendukung yang diberikan. Sebagai contoh diambil asrama Universitas Gadjah Mada (UGM), Institut Teknologi Bandung (ITB), Universitas Indonesia (UI), Universitas Padjadjaran (UNPAD), dan asrama Universitas Telkom (TEL-U). Data dikumpulkan melalui pencarian di internet ditambah dengan verifikasi data melalui wawancara dengan pengguna. Data asrama dielaborasi pada tabel 1.

Kelengkapan fasilitas dan ruang komunal asrama ditemukan berbeda antar asrama bergantung pada kebijakan setiap kampus dan pengelola asrama. Pada tabel terlihat bahwa kelengkapan fasilitas antar asrama berbeda satu dengan lainnya. Fasilitas terlengkap ditemukan pada asrama Unpad Bale Padjadjaran dengan total 15 jenis fasilitas, diikuti asrama UGM dengan 14 jenis fasilitas. Pada asrama Unpad, fasilitas asrama bahkan telah mengikutkan area luar bangunan sebagai area belajar dengan keberadaan fasilitas gazeboo.

Adapun kelengkapan fasilitas setiap kamar tidak sama. Bentuk perabot dan kelengkapan disesuaikan dengan kebijakan pengelola asrama. Terdapat asrama dengan tempat tidur model tingkat (bunkbed), terdapat juga asrama dengan tempat tidur model individual. Hal yang sama ditemui pada fasilitas lemari pakaian dan meja belajar. Perabot yang tidak ditemukan pada setiap kamar adalah rak buku, kecuali di asrama UI. 
Tidak ditemukan kehadiran pantry di dalam kamar, tetapi beberapa asrama memiliki fasilitas dapur ataupun pantry bersama. Sama halnya dengan fasilitas cuci atau laundry. Ditemukan pula asrama tanpa kedua fasilitas tersebut dalam gedung. Hal kedua agak bertentangan dengan hasil penelitian Amole (2010) yang menyarankan pembedaan fasilitas bagi mahasiswa dan mahasiswi, bahwa mahasiswi membutuhkan kehadiran ruang domestik seperti dapur dan area cuci. Disebutkan pula bahwa area dapur dan area cuci bisa menjadi ruang komunal untuk berinteraksi antar penghuni asrama. Beberapa asrama memberikan fasilitas mushola yang sebetulnya mungkin kurang diperlukan, mengingat mahasiswa dapat melaksanakan kegiatan ibadah di kamar masing-masing.

Asrama Unpad memiliki ruang rekreasi yang sangat baik berupa studio musik, ruang karaoke dan ruang fitness. Ruang-ruang ini dapat menjadi ruang komunal yang efektif untuk menjalin hubungan sosial antar penghuni. Melihat kelengkapan asrama Unpad Bale Padjadjaran, bisa dikatakan bahwa asrama ini memberikan layanan yang cukup lengkap dan berkelas untuk tingkat universitas, bahkan tergolong mewah.

\subsection{Perbandingan Luasan Kamar dan Tingkat Kepadatan}

Luas kamar setiap asrama berbeda-beda. Meskipun demikian, berdasarkan pengamatan, ditemukan bahwa luas setiap kamar telah sesuai dengan standar minimum berdasarkan standar internasional, antara lain minimum luas ruang untuk 2-3 orang adalah 10,2 m2. Jumlah penghuni pada setiap kamar asrama bervariasi antara 1-3 orang pada universitas negeri, sementara Universitas Telkom menempatkan 4 mahasiswa dengan model tempat tidur bertingkat.

Didapatkan 3 tipologi kamar dari hasil perbandingan ini, yaitu kamar untuk 2-3 orang merangkap ruang belajar dengan kamar mandi bersama dan tempat tidur individu; kamar semi kluster dengan kamar tidur individu yang dihuni 1-2 orang dilengkapi ruang belajar bersama yang terpisah dari kamar tidur dan kamar mandi bersama; kamar yang dihuni 4 orang merangkap ruang belajar dengan tempat tidur tingkat dan kamar mandi bersama.

\subsection{Perbandingan Peruntukkan dengan Kelengkapan Fasilitas}

Peruntukan hunian asrama berbeda-beda di setiap kampus. ITB memperuntukkan asrama bagi mahasiswa tahun persiapan bersama tingkat 1 dan mahasiswa Bidik Misi. Asrama Unpad Bale Padjadjaran diperuntukkan bagi mahasiswa tahun pertama Fakultas Kedokteran. Asrama UI ditujukkan bagi mahasiswa baru yang berasal dari Jabodetabek. Asrama UGM ditujukkan bagi mahasiswa baru. Asrama Universitas Telkom diperuntukkan bagi mahasiswa tahun pertama tingkat 1 . Dengan demikian, peruntukkan asrama tidak sama antar universitas. 


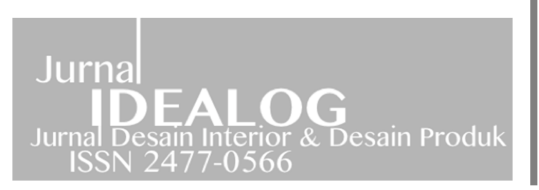

\section{Kesimpulan}

Dari data hasil komparasi fasilitas antar universitas dari 5 kampus yang dibandingkan, dapat disimpulkan bahwa terdapat keragaman fasilitas dan perbedaan peruntukkan asrama universitas di Indonesia. Kelengkapan fasilitas dan peruntukkan asrama universitas di Indonesia masih belum terstandar. Setiap manajemen universitas memiliki kebijakan berbeda dalam penyelenggaraan asrama

Ditemukan bahwa belum semua asrama memberikan kelengkapan fasilitas sesuai saran Keppres maupun saran hasil penelitian seperti perlunya fasilitas dapur, ruang cuci (laundry), ruang belajar, area rekreasi, area olahraga, perpustakaan. Malah ditemukan bahwa tidak satupun dari asrama yang distudi memberikan fasilitas area cuci dan perpustakaan.

Ragam tipe asrama perlu dipelajari dan diusulkan sesuai konteks kebutuhan mahasiswa Indonesia. Keragaman tipe bisa memberikan pilihan pada mahasiswa untuk memilih asrama yang sesuai dengan kebutuhan mereka. Masalah muncul karena asrama-asrama yang menjadi objek studi telah menentukan jenis penghuni asrama dan hanya terbuka bagi mahasiswa dengan kriteria tertentu, misalnya mahasiswa baru saja, atau mahasiswa program studi $\mathrm{X}$ saja, dan sebagainya. Hal ini justru menjadikan asrama bersifat eksklusif ketika asrama seharusnya inklusif. Untuk itu, jika dimaksudkan untuk memfasilitasi mahasiswa secara umum, asrama perlu dibuka dan ditawarkan pada setiap mahasiswa yang membutuhkan. 


\section{Hasil}

Tabel 1. Elaborasi Data Asrama Universitas di Beberapa Universitas di Indonesia

\begin{tabular}{|c|c|c|c|c|c|}
\hline & ITB (JATINANGOR) & $\begin{array}{c}\text { UNPAD (BALE } \\
\text { PAJAJARAN 2-4) }\end{array}$ & UI & UGM & Universitas Telkom \\
\hline Asrama Putra & $\sqrt{ }$ & $\sqrt{ }$ & $\sqrt{ }$ & $\sqrt{ }$ & $\sqrt{ }$ \\
\hline Asrama Putri & $\sqrt{ }$ & $\sqrt{ }$ & $\sqrt{ }$ & $\sqrt{ }$ & $\sqrt{ }$ \\
\hline \multicolumn{6}{|c|}{ FASILITAS KAMAR } \\
\hline Tempat Tidur & $\sqrt{ }$ & $\sqrt{ }$ & $\sqrt{ }$ & $\sqrt{ }$ & $\sqrt{ }$ \\
\hline Lemari Pakaian & $\sqrt{ }$ & $\sqrt{ }$ & $\sqrt{ }$ & $\sqrt{ }$ & $\sqrt{ }$ \\
\hline Meja Belajar & $\sqrt{ }$ & $\sqrt{ }$ & $\sqrt{ }$ & $\sqrt{ }$ & $\sqrt{ }$ \\
\hline Kursi & $\sqrt{ }$ & $\sqrt{ }$ & $\sqrt{ }$ & $\sqrt{ }$ & $\sqrt{ }$ \\
\hline Kamar Mandi & $\sqrt{ }$ & $\sqrt{ }$ & & $\sqrt{ }$ & $\sqrt{ }$ \\
\hline Rak Buku & & & $\sqrt{ }$ & & \\
\hline Coffee Table & & & & $\sqrt{ }$ & \\
\hline \multicolumn{6}{|l|}{ Laundry/ruang cuci } \\
\hline Sarana Olahraga & $\sqrt{ }$ & $\sqrt{ }$ & & $\sqrt{ }$ & \\
\hline Mushola & & $\sqrt{ }$ & $\sqrt{ }$ & $\sqrt{ }$ & $\sqrt{ }$ \\
\hline Ruang Belajar (indoor) & & & & $\sqrt{ }$ & \\
\hline Ruang TV & & & & & $\sqrt{ }$ \\
\hline $\begin{array}{l}\text { Area Rekreasi (Studio } \\
\text { Musik, Ruang Karaoke) }\end{array}$ & & $\sqrt{ }$ & & & \\
\hline
\end{tabular}


Jurnal Desain Interior \& Desain Produk

Vol.1 No.2, Agustus 2016

ISSN 2477 - 0566

\begin{tabular}{|c|c|c|c|c|c|}
\hline Area belajar outdoor & & $\sqrt{ }$ & & & \\
\hline Kamar mandi umum & & & $\sqrt{ }$ & & \\
\hline Dapur/pantry & & $\sqrt{ }$ & & $\sqrt{ }$ & \\
\hline Guestroom & & $\sqrt{ }$ & & & \\
\hline Lobby & & & & $\sqrt{ }$ & $\sqrt{ }$ \\
\hline Ruang Pertemuan/aula & & & & $\sqrt{ }$ & \\
\hline Kantin & & $\sqrt{ }$ & $\sqrt{ }$ & $\sqrt{ }$ & \\
\hline Minimart & & $\sqrt{ }$ & & $\sqrt{ }$ & \\
\hline ATM & & & $\sqrt{ }$ & & \\
\hline $\begin{array}{c}\text { Fasilitas Photo Copy, } \\
\text { Warnet dan } \\
\text { ATK/Koperasi }\end{array}$ & $\sqrt{ }$ & $\sqrt{ }$ & & & \\
\hline $\begin{array}{l}\text { Fasilitas lainnya (tour \& } \\
\text { travel. Layanan dokumen, } \\
\text { senior residence) }\end{array}$ & & $\sqrt{ }$ & & & $\sqrt{ }$ \\
\hline $\begin{array}{c}\text { TOTAL Kelengkapan } \\
\text { Fasilitas }\end{array}$ & 7 & 15 & 9 & 14 & 9 \\
\hline \multicolumn{6}{|c|}{ LAYANAN ASRAMA } \\
\hline Wi-Fi & $\sqrt{ }$ & $\sqrt{ }$ & $\sqrt{ }$ & $\sqrt{ }$ & $\sqrt{ }$ \\
\hline Cleaning service & & $\sqrt{ }$ & & & \\
\hline Laundry & & & & $\sqrt{ }$ & $\sqrt{ }$ \\
\hline \multicolumn{6}{|c|}{ UKURAN KAMAR } \\
\hline \multirow{2}{*}{ Luas Kamar Putra } & & & 2,5x3 Meter(Single) & 2,5x4 Meter & $12 \mathrm{~m} 2$ \\
\hline & & & $3 \times 5$ Meter (2-3org) & & \\
\hline
\end{tabular}




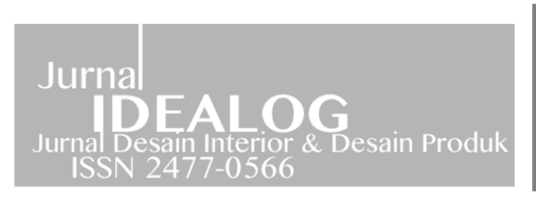

Jurnal I D E A L O G

Jurnal Desain Interior \& Desain Produk

Vol.1 No.2, Agustus 2016

ISSN 2477 - 0566

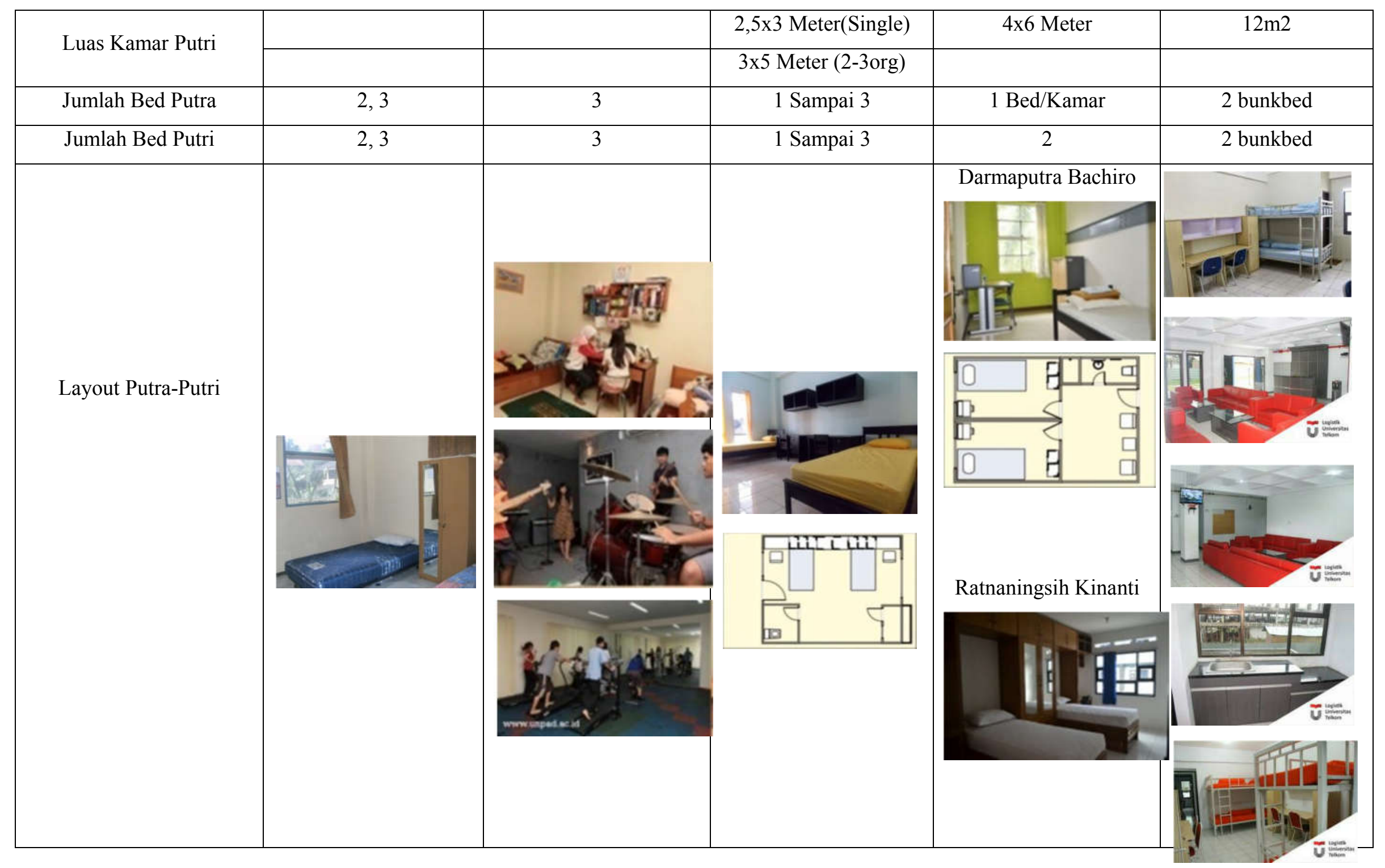


Jurnal I D E A L O G

Jurnal Desain Interior \& Desain Produk

Vol.1 No.2, Agustus 2016

ISSN 2477 - 0566

\begin{tabular}{|c|c|c|c|c|}
\hline & & & & \\
\hline \multirow{2}{*}{ Peruntukkan } & Mahasiswa TPB & Program Wajib & Mahasiswa Baru & Mahasiswa Baru \\
Tingkat 1, Bidik Misi & $\begin{array}{c}\text { Asrama Tahun Pertama } \\
\text { Fakultas Kedokteran }\end{array}$ & Mahasiswa TPB \\
Tingkat 1 & & \\
\hline
\end{tabular}




\section{Daftar Pustaka}

[1] Baum, A., \& Valins, S. 1979. Architectural mediation of residential density and control: Crowding and the regulation of social contact. Advances in experimental social psychology, 12, 131-175.

[2] Case, F. D. 1981. Dormitory Architecture Influences Patterns of Student Social-Relations Over Time. Environment and Behavior, 13(1), 23-41.

[3] Clemons, S. A., Banning, J. H., \& McKelfresh, D. A. 2004. The Importance of Sense of Place and Sense of Self in Residence Hall Room Design. Journal of Student Affairs, 13, 8-6.

[4] De Chiara \& Callender. 1980. Time Saver Standard for building types $2^{\text {nd }}$ edition. Mc Graww Hill Book Company, New York.

[5] Amole, Dolapo. 2012. Gender Differences In User Responses To Students Housing. Aice-Bs 2010 Kuching Asia Pacific International Conference On Environment-Behaviour Studies, Malaysia, 7-9 December 2010. Procedia Social And Behavioral Sciences 38. 89 - 99

[6] Epstein, Y.M., 1981. Crowding Stress And Human Behavior. Journal Of Social Issues, 37(1), Pp.126-144.

[7] Haryadi, B Setiawan. 1995. Arsitektur Lingkungan dan Perilaku. Proyek Pengembangan Pusat Studi Lingkungan. Direktorat Jenderal Pendidikan Tinggi Departemen Pendidikan dan Kebudayaan, Republik Indonesia.

[8] Heilweil, M. 1973. The influence of dormitory architecture on resident behavior. Environment and Behavior, 5(4), 377. Vol. 5 no. 4, December 1973. SAGE Publications, Inc.

[9] Khajehzadeh, Iman, Vale Brenda. 2014. Shared Space in a Student Dorm: A Post Occupancy Evaluation. Across Architectural Research through Practice: 48th International Conference of the Architectural Science Association, pp. 163174

[10] Kiliçaslan, Hare. 2013. Design of Living Spaces in Dormitories. Procedia Social and Behavioral Sciences 92 (2013) 445-451

[11] Muslim, Muhammad Hilmy, Hafazah Abdul Karim, Ishak Che Abdullah. 2012. Satisfaction Of Student's Living Environment Between On-Campus And Off-Campus Settings: A Conceptual Overview. Procedia - Social And Behavioral Sciences 68 (2012) $601-614$

[12] Null, Robert L. 1980. University Residence Hall Suites: A Progression of Approaches to Evaluation Research. Housing and Society Vol. 7 No. 1., 67-76 